\title{
Current achievements on superplasticity and related phenomena at the Institute for Metals Superplasticity Problems
}

\author{
R. R. Mulyukov, A. A. Nazarov, R. M. Imayev ${ }^{\dagger}$ \\ †renat_imayev@mail.ru
}

Institute for Metals Superplasticity Problems of RAS, 39 Khalturin str., Ufa, 450001, Russia

\begin{abstract}
A short review on the results of research and development on superplasticity of alloys and related processes such as grain refinement, solid state bonding carried out at the Institute for Metals Superplasticity of the Russian Academy of Sciences (IMSP RAS) is given. One of the most important contributions of IMSP RAS to the fundamentals of superplasticity consists in a development of the theory of superplastic flow based on the notion of cooperative grain boundary sliding. Main bases and results of this theory are presented. Since achieving superplasticity requires the formation of ultrafine grained microstructures in alloys, methods for grain refinement have been developed. The principles of the method of multiple isothermal forging invented at IMSP RAS, which allows refining grains in a wide range of metals and alloys down to the submicron and nanometer sizes, are reported. The method is capable of fabricating large bulk and sheet semiproducts with an UFG structure. The most important achievements in enhancing the characteristics of superplasticity of aluminum and intermetallic alloys are reported. Also, significant results have been obtained in the studies of diffusion bonding of similar and dissimilar materials, superplastic forming of hollow structures. These results have been used in the development of a technology for fabrication a titanium wide-chord hollow fan blade for the indigenous fifth-generation aircraft engine PD14, which has been certified quite recently. Finally, results of finite-element modeling of superplastic forming processes are reviewed shortly.
\end{abstract}

Keywords: superplastic deformation, grain refinement, ultrafine-grained structure, diffusion bonding, superplastic forming.

\section{Introduction}

The phenomenon of structural superplasticity first discovered by Pearson in 1934 [1] and first studied systematically by Bochvar and Sviderskaya in 1946 [2] is still a topical issue of the materials science and technology due to promising opportunities it provides for the engineering production. The interest to this topic is confirmed by numerous publications and international conferences, the latest of which, ICSAM-2018, has been held quite recently in Saint-Petersburg [3]. The world community knows many examples of the realization on superplastic deformation in advanced metal forming technologies. Fundamental and applied researches in the field of superplasticity and related phenomena have always been extensively carried out at the Institute for Metals Superplasticity Problems of the Russian Academy of Sciences (IMSP RAS) [4,5]. The most recent results of these studies have been summarized in the multi-author monograph written by the leading researchers of IMSP RAS [6] and joint monograph [7]. In the present paper, we make a short review of the most important achievements of IMSP RAS in research and development on superplasticity and related problems such as grain refinement, solid state bonding, superplastic forming, theory and simulation etc. in the last decades.

\section{Theory of structural superplasticity}

Since the beginning of extensive studies on superplasticity, many different models have been proposed to rationalize the well known empirical relationship between the stress and strain rate of optimum superplasticity [8]:

$$
\dot{\varepsilon}=A \frac{G b}{k T}\left(\frac{b}{d}\right)^{p}\left(\frac{\sigma}{G}\right)^{n} \cdot D_{0 b} \exp \left(-\frac{Q_{b}}{R T}\right),
$$

where $A$ is a constant, $G$ shear modulus, $b$ interatomic distance, $k$ the Boltzmann coefficient, $D_{0}$ and $Q_{b}$ the pre-exponential factor and activation energy for the grain boundary diffusion coefficient, $p \approx 2 \div 3, n \approx 2$.

Most of the models based on the limiting role of processes accommodating the grain boundary sliding (GBS) resulted in a kinetic equation similar to Eq. (1), where the strain rate sensitivity of the flow stress, $m=1 / n$, has the value of 0.5 that is in good agreement with the experimental results $[8,9]$.

We critically re-analyzed these models and found that, however, independently of the accommodating process (diffusion or dislocation emission), all models resulted in similar relationships, which were typically obtained for diffusion creep, i.e. with $m=1$ [6]. Thus, we have demonstrated that the real deformation process during superplastic deformation cannot be controlled by a single mechanism but should be a combination of mechanisms. 
The most rigorous theoretical analysis of the superplastic flow was done at IMSP RAS by A.I. Pshenichnyuk and O. A. Kaibyshev. Basing on the experimental data, which testify on a localization of superplastic deformation (SPD) in cooperative GBS bands [10], they showed that the ubiquity of superplastic behavior of different materials (alloys, ceramics, composites etc.) consisted not in the kinetics of accommodation of GBS in individual GBs, but in the formation of cooperative GBS bands. This approach allowed the authors to calculate the interval of optimal superplasticity, describe the kinetic equation including that for high strain rate superplasticity. The authors suggested that the uniformity of strain during superplastic deformation that is the main reason for the lack of failure up to large elongations was related to a large-scale self-organization of the plastic flow, due to which the deformation was considered on the macrolevel as an integrated coherent process. The mechanism that provides such a coherency is the formation of cooperative GBS, which was discovered in experimental studies [10]. The formation of a cooperative GBS band can occur by a straightening of a triple junction, i.e. by a change of a dihedral angle between a sliding and neighboring GB from the equilibrium one equal to $2 \pi / 3$, to $\pi$ [11]. This is a barrier process and at given temperature and shear stress on the GB plane local migration is underwent by all GBs having the lengths in a certain interval $\left[L_{1}, L_{2}\right]$. If a possible band crossing the sample consists of $n$ grains, on an attainment of a certain threshold value $p_{c} n\left(0<p_{c}<1\right)$ of the fraction of locally migrated GBs the active GBs will involve all the rest GBs of the band into cooperative sliding, and a band of cooperative GBS is formed. If the maximum value of possible cooperative GBS bands in the sample is equal to $M_{0}$, the average number of bands active in the given conditions $\langle M\rangle$, and the velocity of sliding in the band $V$, then the strain rate can be calculated as

$$
\dot{\varepsilon}=\frac{\langle M\rangle}{M_{0}} \frac{V}{\sqrt{2} d} .
$$

Then to obtain the kinetic equation of superplastic deformation one should calculate the dependence of the relative number of active bands and sliding rate along them in the conditions of deformation. As one can see from Eq. (2), the main difference of this model from others is in the factor $\langle M>| M_{0}$, which characterizes the participation of not of a few, but of a large number of grains in the organization of the plastic flow. In its essence, this factor determines the range of superplastic deformation in the space of material parameters and deformation conditions.

The results of an analysis of the kinetics of superplastic deformation in all three regions and the limits of superplastic deformation based on this approach were summarized in the monograph [12]. This theory based on cooperative GBS was capable to satisfactorily explain the most of experimentally observed features of superplastic deformation and, by our opinion, it is the most complete and universal model of this phenomenon nowadays.

\section{Processing ultrafine grained structures for superplasticity}

\subsection{Bulk billets}

Since superplasticity is observed only with alloys having ultrafine grained (UFG) microstructures, grain refinement has always been given a great importance at IMSP RAS. To process bulk UFG billets, the method of hot isothermal deformation was used $[4,5]$. When doing this, temperature and strain rate were chosen in order to provide a maximally intensive development of dynamic recrystallization. This idea also turned out to be very fruitful with respect to the refinement of grains to sizes below $1 \mu \mathrm{m}$ and even $100 \mathrm{~nm}$ and resulted in the development of an original method of multiple isothermal forging (MIF) [13-17]. In the last decades, this method have been developed further and successfully tested on many new materials.

The main idea of MIF is to take the full advantage of dynamic recrystallization and other thermally activated processes for the grain refinement in metals and alloys. It is based on the use of the relationship between the size of recrystallized grains and conditions of isothermal deformation (temperature and strain rate): $d=d(T, \dot{\varepsilon})$. To implement the technique, it is necessary to solve two main tasks:

i) creating a uniform, equiaxed fine-grained structure with a large fraction of high-angle grain boundaries having no sharp crystallographic texture in large-scale billets;

ii) stepwise reduction of the grain size down to the desired scale, for example, to a few hundred nanometers.

The first task includes three steps. On the first, an ingot of a metal or alloy having the cast structure is subjected to a preliminary deformation treatment by forging, extrusion, rolling etc. to obtain a fine grained structure. On the second stage model samples are studied to establish basic relationships between the mechanisms of deformation and kinetics of recrystallization, their dependencies on the initial microstructure, morphology and dispersivity of phases, and to find the most favored values of the strain rate and temperature for the dynamic recrystallization. On the last stage this knowledge is used to obtain uniform UFG structures in large scale billets. For this, the scheme of MIF is used (Fig. 1).

This scheme represents a cycle of operations including upsetting, turning and drawing, as a result of which, at the end of the cycle, the billet acquires approximately its original shape and dimensions. A stepwise reduction of the grain size occurs due to a stepwise decrease of the temperature of the deformation processing of the billet. Numerous studies have shown that the MIF with a stepwise decrease in the temperature enables grain refinement in a material down to the nano-sized range avoiding its failure during the processing [6,7].

The dimensions of semiproducts which can be processed by this method depend on the capacity of a press used for forging. The largest UFG semiproducts were fabricated at IMSP RAS from titanium alloy VT6 on a press with 1600 
tons capacity. For example, in a rod with diameter $200 \mathrm{~mm}$ and length $300 \mathrm{~mm}$ average grain size of about $0.4 \mu \mathrm{m}$ was obtained [6]. The above stated principles of producing bulk semi-products with a uniform UFG structure have been successfully applied at IMSP RAS to dozens of different metals and alloys, such as titanium and titanium-based alloys, steels, aluminum, magnesium, copper, nickel based alloys including hard-to-deform nickel-based superalloys and intermetallic alloys (based on the compounds TiAl, $\left.\mathrm{Ti}_{3} \mathrm{Al}, \mathrm{Ti}_{2} \mathrm{AlNb}\right)[5,13-17]$.

To give an example, presented in Fig. 2 are EBSD maps of the microstructure of $\mathrm{Zr}$ alloy E125 processed by MIF down to the temperatures $T=700^{\circ} \mathrm{C}$ and $450^{\circ} \mathrm{C}$ [17].

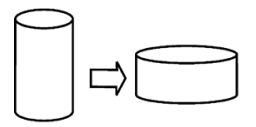

Pass 1: Upsetting
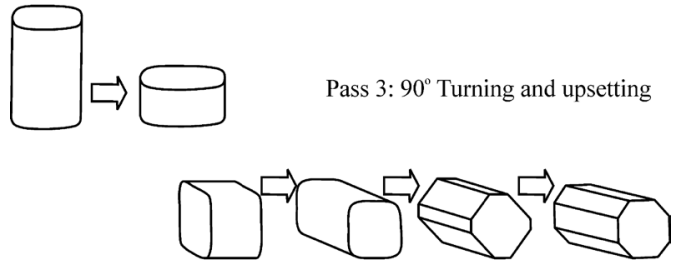

Pass 4: Drawing

Fig. 1. The scheme of multiple isothermal forging.
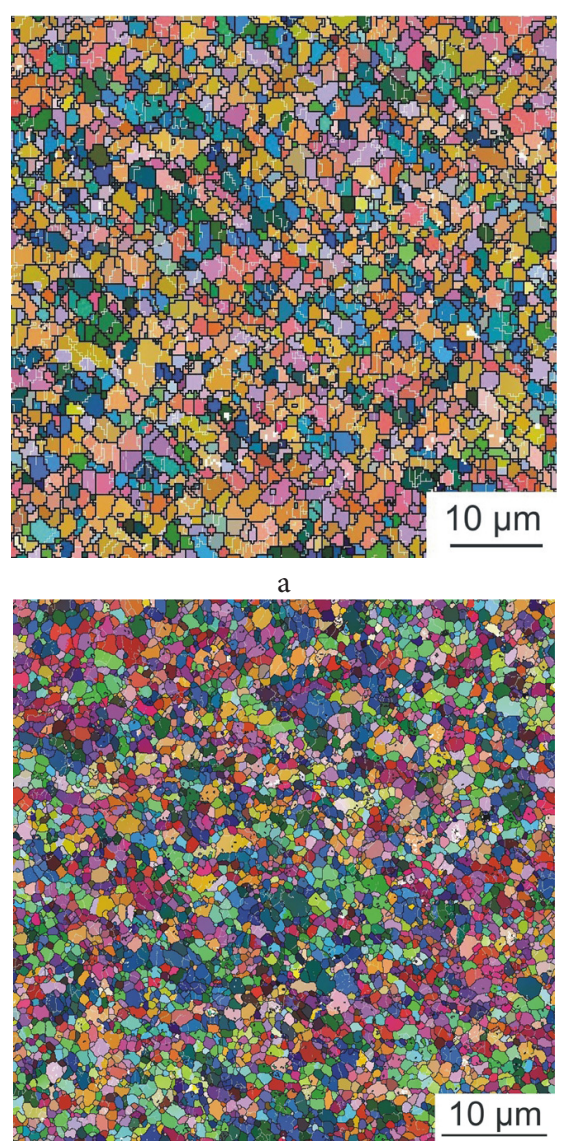

b

Fig. 2. EBSD images of the microstructure of $\mathrm{Zr}$ alloy E125 after multiple isothermal forging at $T=700^{\circ} \mathrm{C}$ (average grain size $d=1.5 \mu \mathrm{m})(\mathrm{a})$ and $T=450^{\circ} \mathrm{C}(d=0.5 \mu \mathrm{m})(\mathrm{b})$.

\subsection{Sheet semiproducts}

In the aircraft engineering, aircraft engine building and many other industries sheet semi-products of alloys with enhanced service properties are in a great demand. Bulk UFG semiproducts processed by MIF are characterized by an extraordinarily high workability and can be used to fabricate sheets with an UFG structure. The method of fabricating UFG titanium sheet elaborated at IMSP RAS $[18,19]$ is based on warm rolling of bulk UFG billets. The preliminarily prepared UFG structure allows for achieving large and uniform plastic strains over the whole volume of a material during sheet rolling. Rolling of a billet is performed in a specified temperature range. The upper bound of the temperature interval to which the billet to be rolled is heated is defined by the temperature of the final step of its preliminary MIF treatment. This means that in the structure of the sheet product under rolling the grain size achieved by the preceding treatment will be maintained during its intermediate reheating for rolling. The lower bound of the rolling temperature range is restricted by the workability of the UFG material.

For example, after the final step of MIF at the temperature of $T=600^{\circ} \mathrm{C}$ a billet of VT6 alloy has a uniform structure with the grain size of $d=300-400 \mathrm{~nm}$. Warm rolling was performed at a temperature of about $T=600^{\circ} \mathrm{C}$ and the strain rates $\dot{\varepsilon}=10^{-2}-10^{-1} \mathrm{~s}^{-1}$ with a $10-15 \%$ reduction and intermediate reheating of the billet at each pass. Using this method, sheet products with the thickness of 2 and $0.8 \mathrm{~mm}$ have been fabricated [20].

The UFG sheet materials demonstrate high superplasticity characteristics at lower deformation temperatures than finegrained materials [6,7]. For instance, at the temperature of $T=700^{\circ} \mathrm{C}$ and strain rates $\dot{\varepsilon}=10^{-3}-10^{-2} \mathrm{~s}^{-1}$, a high strain rate sensitivity of the flow stress $(m=0.5)$ is observed and the magnitude of the relative elongation reaches $\delta=900 \%$. Flow stresses $\sigma \approx 45 \mathrm{MPa}$, which are observed in the UFG material at the temperature $T=700^{\circ} \mathrm{C}$ and at low strain rates $\left(\dot{\varepsilon}=10^{-4} \mathrm{~s}^{-1}\right)$, are typical of titanium alloy VT6 with a usual fine-grained structure $(d=5-10 \mu \mathrm{m})$, however, at higher deformation temperatures, $T=900-925^{\circ} \mathrm{C}$.

Fabrication of UFG sheets with enhanced superplastic properties at relatively low temperatures is very important for the use in integral technologies of manufacturing multilayer structures by means of SPF and diffusion bonding.

\section{Enhanced superplastic characteristics of UFG alloys}

\subsection{Extraordinary superplastic elongation of aluminum alloy $01570 \mathrm{C}$}

Extraordinarily high superplastic elongation of the Russian aluminum alloy $\mathrm{O} 1570 \mathrm{C}$ (Al-5Mg-0.18Mn-0.2Sc-0.08Zr$0.01 \mathrm{Fe}-0.01 \mathrm{Si}(\mathrm{wt} \%))$ has been achieved recently at IMSP RAS [21]. A very uniform UFG structure with the grain size about $d=1 \mu \mathrm{m}$ and fraction of high-angle GBs about $87 \%$ was processed by equal channel angular pressing of plate samples at $T=325^{\circ} \mathrm{C}$ to a strain about 10 . This UFG alloy exhibited superior superplasticity characteristics in 
tension tests: $\delta=3170 \%$ at $T=400^{\circ} \mathrm{C}$ and $\dot{\varepsilon}=1.4 \times 10^{-1} \mathrm{~s}^{-1}$; $\delta=4100 \%$ at $T=450^{\circ} \mathrm{C}$ and $\dot{\varepsilon}=5.6 \times 10^{-2} \mathrm{~s}^{-1}$; and $\delta=3300 \%$ at $T=475^{\circ} \mathrm{C}$ and $\dot{\varepsilon}=1.4 \times 10^{-2} \mathrm{~s}^{-1}$. Such a behavior is caused by a combination of the very uniform microstructure and effect of alloying additions. The correct choice of the alloy, alloying elements and formation of a uniform UFG structure allowed one to achieve an overlap of the strain ratetemperature intervals of the superplastic flow and dynamics recrystallization. Due to this, the grains growing during deformation refined back by recrystallization that stabilized the grain size and resulted in a very high elongation. High grain size stability was also provided by the presence of a significant amount of $\mathrm{Al}_{3}(\mathrm{Sc}, \mathrm{Zr})$ dispersoids. They remained stable even at $T=475^{\circ} \mathrm{C}$ and frequently interacted with grain boundaries and lattice dislocations, preventing thereby both the intense grain growth and the static recovery of structure.

\subsection{Superior superplastic properties of $\gamma$-TiAl intermetallics}

Previous studies have shown that the superplastic behavior of $\gamma$-TiAl intermetallic alloys is in general similar to that of metallic alloys, but occurs at higher homologous temperatures and the typical superplastic elongations are in an interval $\delta=300-800 \%$. Much higher superplastic elongations have been achieved recently at IMSP RAS with the $\gamma$-TiAl alloys. The idea behind the studies resulting in this achievement is based on the fact that intermetallic phases $\gamma$ and $\alpha_{2}$ are characterized by a wide range of homogeneity and can dissolve a relatively large number of elements, which significantly reduce the diffusion mobility of atoms. The most promising alloying element in this respect is niobium, which can be dissolved in both the $\gamma$ and $\alpha_{2}$ phases in an amount of about 10 at. $\%$ [22-24]. Niobium additions increase considerably the activation energy of diffusion in the $\gamma$ and $\alpha_{2}(\alpha)$ phases [25-27] and lead to an improved corrosion resistance [27]. Therefore, niobium additions appear to be most efficient for the stabilization fine-grained microstructure and superplastic deformation $\gamma$-TiAl alloys in air environment.

Consider the superplastic behavior of two $\gamma$-TiAl alloys with an enhanced content of $\mathrm{Nb}$. The first one, Ti-45Al-8Nb-0.2C, contains $3 \%$ of the second phase $\alpha_{2}-\mathrm{Ti}_{3} \mathrm{Al}$ and is a nearly single phase alloy. The second alloy, Ti-43.7Al-4.2Nb-0.5Mo-0.2B-0.2C, contains a significant volume fraction, approximately $30 \%$, of the second phase $\alpha_{2}-\mathrm{Ti}_{3} \mathrm{Al}$. The results shortly presented below of are described in detail in $[28,29]$.

The alloys were subjected to a two-stage thermomechanical treatment. The ingots of the first alloy were preheated at $T=1250^{\circ} \mathrm{C}$ and extruded to a ratio of $7: 1$, then subjected to machining and cutting. After that, the cylindrical workpieces were subjected to unidirectional forging under isothermal conditions at $T=950^{\circ} \mathrm{C}$, $\dot{\varepsilon}=5 \times 10^{-4}-10^{-3} \mathrm{~s}^{-1}$ to a strain of about $80 \%$ and ageing at $\mathrm{T}=800^{\circ} \mathrm{C}$ for $3 \mathrm{~h}$ followed by furnace cooling. The ingots of the $\mathrm{Ti}-43.7 \mathrm{Al}-4.2 \mathrm{Nb}-0.5 \mathrm{Mo}-0.2 \mathrm{~B}-0.2 \mathrm{C}$ alloy were canned using low-carbon steel in order to provide quasi-isothermal conditions and protection from oxidation during forging and then heated up to $T=1200^{\circ} \mathrm{C}$. Die tool was preheated up to $T=950^{\circ} \mathrm{C}$. The first hot forging was fulfilled at a strain rate of $\dot{\varepsilon}=10^{-2} \times 10^{-1} \mathrm{~s}^{-1}$. After the first-stage, the workpiece was decanned and subjected to intermediate annealing. The second stage was conducted under isothermal conditions at $T=950^{\circ} \mathrm{C}, \dot{\varepsilon} \sim 10^{-3} \mathrm{~s}^{-1}$. At first, it was made in the same forging direction. Thereafter the obtained forging was cut into workpieces, which were subjected to $3 \mathrm{D}$ forging under isothermal conditions at $T=950^{\circ} \mathrm{C}, \dot{\varepsilon} \sim 10^{-3} \mathrm{~s}^{-1}$ followed by ageing at $T=900^{\circ} \mathrm{C}$ for $2 \mathrm{~h}$ and furnace cooling.

After the thermomechanical treatment the Ti-45Al-8Nb-0.2C alloy had a fully refined microstructure with the grain size $d=0.9 \pm 0.2 \mu \mathrm{m}$, while the Ti-43.7Al-4.2Nb-0.5Mo-0.2B-0.2C had a partially refined microstructure: theglobularizedvolumeamounted $V_{\text {glob }}=60 \%$, the size of refined grains $d=0.8 \pm 0.2 \mu \mathrm{m}$. The specimens cut from thermomechanically treated samples exhibited superior superplasticity characteristics in tension tests at $T=1000^{\circ} \mathrm{C}$ and $\dot{\varepsilon}=8.3 \times 10^{-4} \mathrm{~s}^{-1}: \delta=1342 \%, \sigma_{30}=34 \mathrm{MPa}$ and $m=0.66$ for Ti-45Al-8Nb-0.2C and $\delta=2860 \%, \sigma_{30}=25 \mathrm{MPa}$ and $m=0.68$ for Ti-43.7Al-4.2Nb-0.5Mo-0.2B-0.2C (Fig. 3). Microstructural studies have shown that the grain size of both alloys is very stable during deformation. This is caused by high content of niobium which impedes the grain growth during superplastic flow in the $\gamma$-TiAl alloys studied. The microstructural stability against grain growth during superplastic flow is also supported by a higher amount of the second $\alpha_{2}$ phase.

The superplastic elongation of $\delta=2860 \%$ achieved in these studies is a record value for intermetallic alloys.

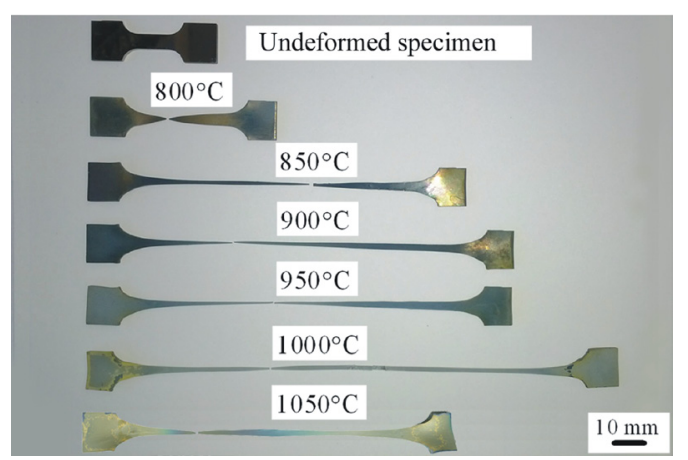

a

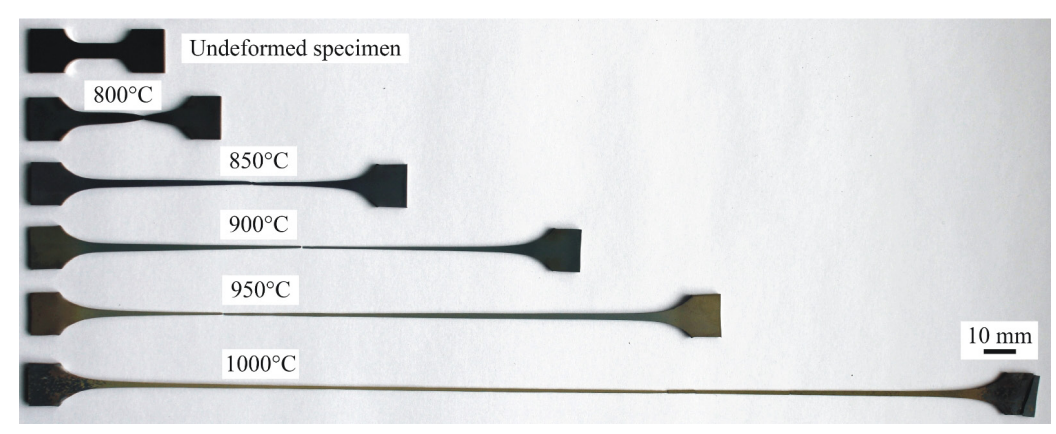

b

Fig. 3. Photos of samples of $\gamma$-TiAl alloys Ti-45Al-8Nb-0.2C (a) and Ti-43.7Al-4.2Nb-0.5Mo-0.2B-0.2C (b) before and after tensile tests at $\dot{\varepsilon}=8.3 \times 10^{-4} \mathrm{~s}^{-1}$ using specimens with a gauge part $10 \times 5 \times 2 \mathrm{~mm}^{3}$. 


\section{Diffusion bonding of UFG metals and alloys}

\subsection{Bonding of similar materials}

The quality of diffusion bonding (DB) essentially depends on the welding conditions, primarily on the temperature and pressure or applied strain. The studies accomplished at IMSP RAS over the last decades have shown that DB under conditions of superplasticity significantly reduces the time required for the formation of a high-quality solid-phase bonding when compared with classical DB [30,31]. Accelerated pore healing in a solid-phase bonding is caused by the development of GBS during superplastic deformation [30]. DB of industrial sheets of titanium alloy VT6 (Ti-6Al-4V) with a grain size of $d=5-10 \mu \mathrm{m}$ is carried out at temperatures $T=900-925^{\circ} \mathrm{C}$, which correspond to the optimal temperature conditions for the occurrence of the superplasticity effect in the material.

A reduction of the grain size increases the total length of grain boundaries in the material that leads to an increase in the contribution of the GBS to total deformation. When bonding UFG sheets of titanium alloy VT6, the welding temperature can be essentially lowered [32]. For instance, with an initial grain size of $d=400 \mathrm{~nm}$, a high-quality bonding has been obtained at the temperature of $T=650^{\circ} \mathrm{C}$, and with $d=200 \mathrm{~nm}$ at $T=600^{\circ} \mathrm{C}$. Of a great practical interest is the DB of industrial semi-products using UFG layers. An example of such bonding is presented in Fig. 4.

As one can see from the figure, a high quality solid joint is obtained. The strength of this joint can be equal to that of the joined material or even higher.

\subsection{Bonding of dissimilar materials}

Using UFG intermediate layers allows one for diffusion bonding of dissimilar materials direct bonding of which is not possible or results in a low quality of the joints. In the last decades, DB of a number of dissimilar pairs has been studied at IMSP RAS. As an example, Fig. 5 demonstrates a full-scale part "support" for an aircraft engine consisting of two diffusion bonded workpieces. The initial workpieces were fabricated from nickel superalloy EI698 and steel VNS63-Sh. As an intermediate layer, cold rolled Ni film was used. Mechanical tests showed that the pull strength of the joint was $1100 \mathrm{MPa}$, or $85-90 \%$ of the strength of EI698 alloy.

\section{Fabrication of hollow structures using superplastic deformation}

Although the SPF/DB and related processes have been widely used in fabricating complicated hollow structures at many leading aircraft and aircraft engine companies [33-38], the potential of their development is still high. In particular, these processes can be drastically facilitated by the use of UFG sheets. Consider this on an example of a titanium wide-chord hollow fan blade. The use of a UFG titanium sheet as a core of this blade allows one to obtain a significant difference in the yield stresses of the skin and core materials and to accomplish a high-quality joint of the
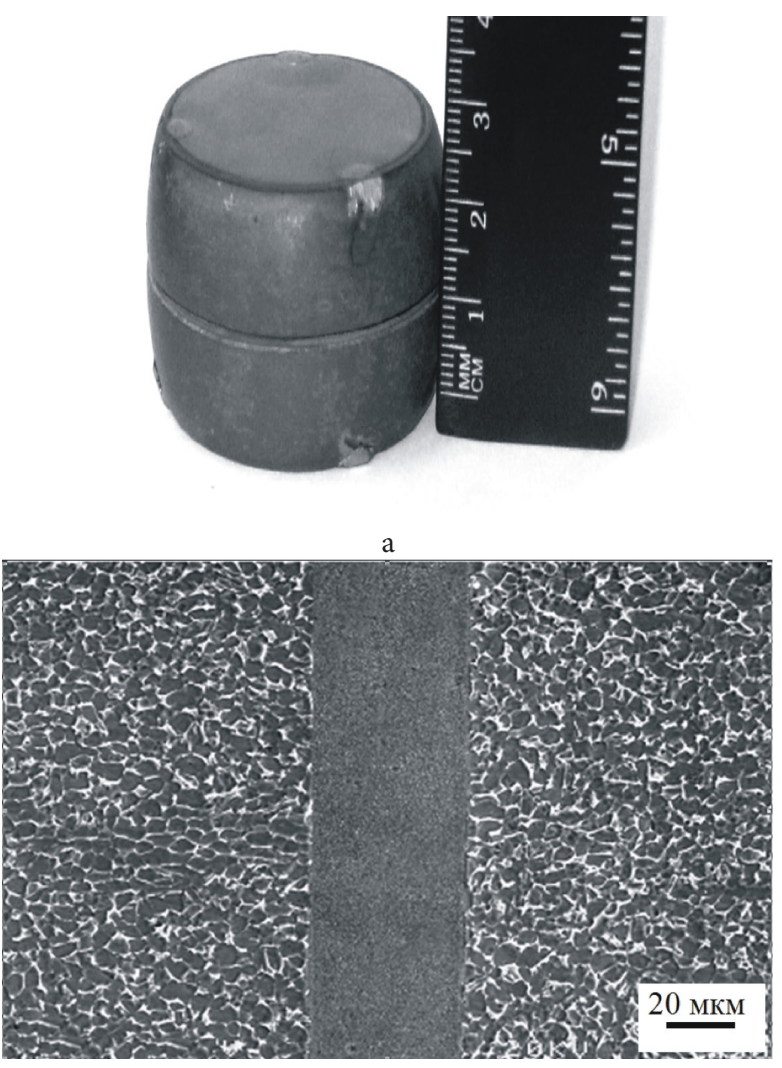

b

Fig. 4. A cylindrical sample obtained by DB of two VT6 alloy billets with grain size $d=5 \mu \mathrm{m}$ using intermediate layer of UFG VT6 alloy with grain size $d=0.5 \mu \mathrm{m}$ (a) and the microstructure of the bonding zone (b); the intermediate layer with a finer structure is clearly seen.

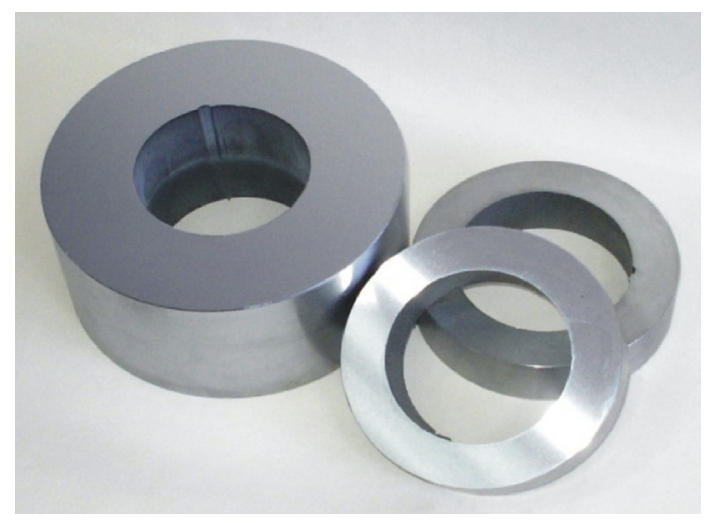

a

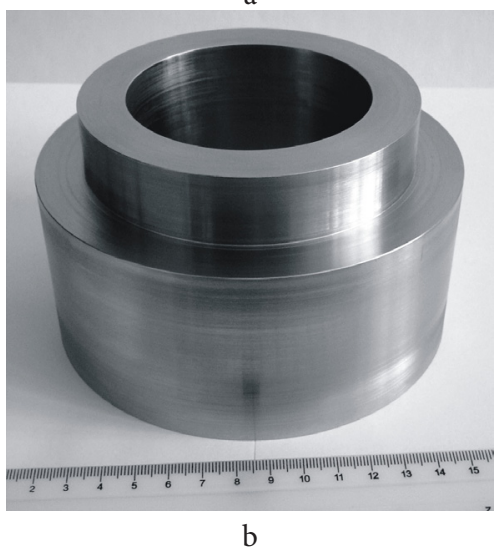

Fig. 5. Diffusion bonded part "support": initial workpieces of $\mathrm{Ni}$ superalloy EI698 (left) and steel VNS63-Sh (right) (a), after DB and tooling (b). 
blade components by diffusion bonding at a relatively low temperature at the expense of strain localization in the bond region. This also provides the required plasticity for the formation of strengthening ribs during SPF.

It is expected that the hollow fan blade fabricated using the UFG sheet core, which serves as a reinforcing element, will exceed the existing analogue (the Rolls-Royce blade) in the production effectiveness and in quality, namely in the structural strength (due to the higher strength of the core and the weld bonds) and damping properties. Moreover, due to the relatively low temperatures of technological operations, the probability of formation of fatigue cracks related to the alpha-case of skin surfaces at high temperatures and the microrelief of the strengthening rib surfaces arising during forming will be lower. Finally, the same factor will reduce the cost price of the product and increase its fabrication efficiency because it will be possible to avoid the formation of brittle alpha-case on the blade surface and exclude laborious and ecologically dangerous operations related to its removal. Moreover, a decrease of the temperature will also decrease the deterioration of the dies, power and labor consumption.

Presented in Fig. 6 is a sample hollow fan blade fabricated from titanium alloy VT6 by the SPF/DB technology at IMSP RAS [39]. A series of such blades were fabricated at IMSP RAS and installed to the new aircraft engine PD-14. These blades successfully passed all tests including engine ring tests and the tests on a "flying laboratory" based on an IL-76 plane.

\section{Finite element modeling of superplastic forming}

Implementation of the SPF/DB technologies is very time and resource consuming. Moreover, the present non-destructive methods do not allow for a satisfactory control of the behavior of inner layers of structures under fabrication. Therefore, finite element modeling (FEM) of this process plays a critical role in the development of SPF/DB technologies. Numerous FEM studies of the SPF of hollow structures have been carried out along with the experimental studies too [6]. These studies allowed one to chose the optimal laws for gas pressure change during forming, find the regimes which provide uniform forming without defects at critical parts of the structures etc.

As an example, Fig. 7 shows the results of a FEM simulation of the SPF of a model hollow blade made of $1.5 \mathrm{~mm}$ thick skip sheets and $0.8 \mathrm{~mm}$ thick core sheet of VT6 alloy at the temperature of $900^{\circ} \mathrm{C}[40]$.

\section{Conclusions}

The present short review shows that currently the studies on all important aspects of superplasticity and related processes are carried out at IMSP RAS beginning from the fundamental studies and finishing with the fabrication of series of products for airspace engineering and other industries. The studies, which began with the establishment of IMSP RAS under the supervision of O.A. Kaibyshev, are developed and broadened.

Just in the days when the authors were working on this paper, an event having a high importance for Russia occurred.

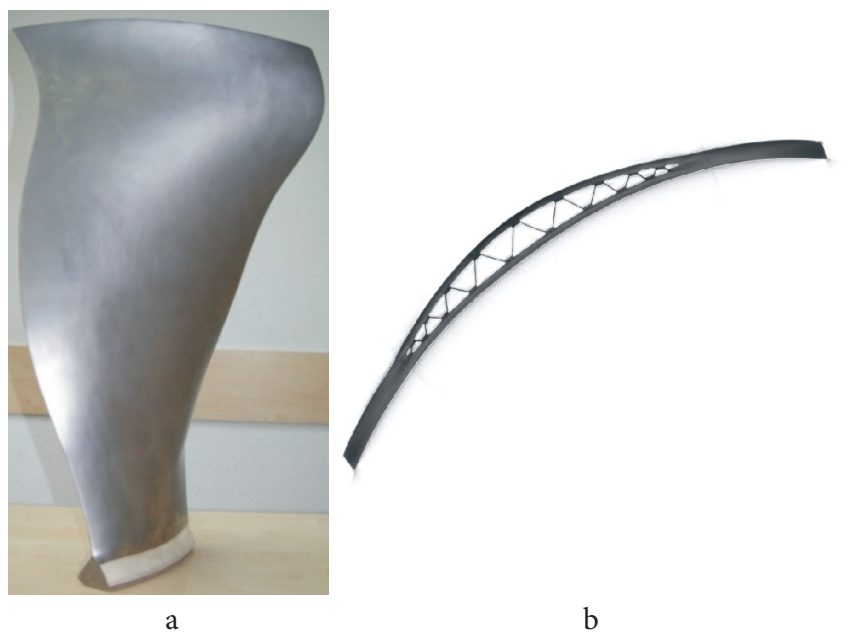

Fig. 6. Hollow fan blade with a UFG core made of titanium alloy VT6 fabricated by the SPF/DB technology: general view (a); cross section (b).

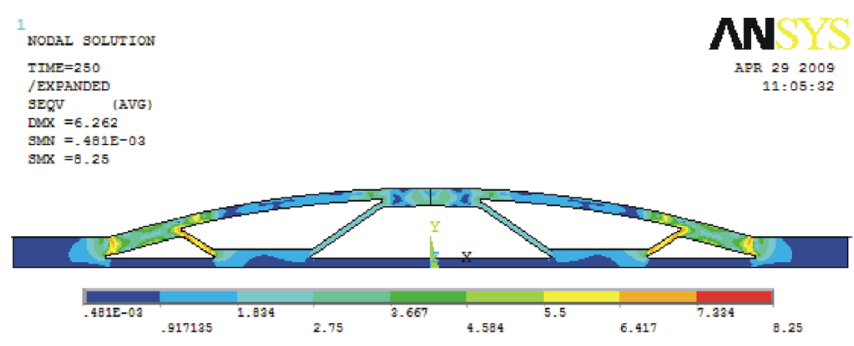

Fig. 7. Cross section of a model blade formed superplastically out of VT6 alloy at $T=600^{\circ} \mathrm{C}$ at at gaz pressure linearly increase from zero in $14 \mathrm{~min}$ [41].

The aircraft engine PD-14, which had been designed, developed and tested in the latest decades, has been certified. Given the fact that new types of air engines are created once per about forty years, this is one of the greatest achievements of the Russian technology. The researchers of the IMSP RAS can be proud that the collective knowledge and competence collected here have also contributed to this achievement.

Acknowledgements. The present work was supported by the State Assignment of the Institute for Metals Superplasticity Problems of the Russian Academy of Sciences.

\section{References}

1. C. E. Pearson. J. Inst. Met. 54, 111 (1934).

2. A. A. Bochvar, Z. A. Sviderskaya. Izv. Akad. Nauk SSSR. Otdel. Tekh. Nauk. 9, 821 (1945). (in Russian)

3. Superplasticity in Advanced Materials - ICSAM 2018. Vol. 385. (Eds. G. Itoh, R. O. Kaibyshev, E.M. Taleff, M. Tikhonova, E. Sato). Def. Diff. Forum, Trans Tech Publ. (2018) 494 p.

4. O. A. Kaibyshev. Superplasticity of Alloys, Intermetallides, and Ceramics. Springer-Verlag, Berlin (1992).

5. O.A. Kaibyshev, F.Z. Utyashev. Superplasticity: Microstructural Refinement and Superplastic Roll Forming. Futurepast Arlington, Virginia, USA (2005) $386 \mathrm{p}$.

6. R.R. Mulyukov, R.M. Imayev, A.A. Nazarov et al. Superplasticity of Ultrafine Grained Alloys: Experimental, 
Theory, Technologies. Nauka, Moscow (2014) 284 p. (in Russian)

7. K.A. Padmanabhan, S.B. Prabu, R.R. Mulyukov, A. Nazarov, R.M. Imayev, S.G. Chowdhury. Superplasticity. Common Basis for a Near-Ubiquitous Phenomenon. Springer-Verlag, Berlin, Heidelberg (2018) $526 \mathrm{p}$.

8. T. G. Nieh, J. Wadsworth, O.D. Sherby. Superplasticity in Metals and Ceramics. Cambridge University Press, Cambridge (1997) $288 \mathrm{p}$.

9. A. Arieli, A. K. Mukherjee. Metall. Trans. A. 13, 717 (1982).

10. V. V. Astanin, O.A. Kaibyshev, S. N. Faizova. Acta Metall. Mater. 42, 2617 (1994).

11. V.V. Astanin, A.V. Sisanbaev, A.I. Pshenichnyuk, O. A. Kaibyshev. Scripta Metall. Mater. 36, 117 (1997).

12. A.P. Zhilayev A.I. Pshenichnyuk. Superplasticity and Grain Boundaries in Ultrafine-Grained materials. Cambridge, Cambridge Intern. Sci. Publ. (2010) 330 p.

13. O.R. Valiakhmetov, R.M. Galeyev, G.A. Salishchev. Fizika Metallov i Metallovedenie. 10, 204 (1990). (in Russian)

14. R. M. Imayev, V.M. Imayev. Scripta Metall. 25, 2041 (1991).

15. G.A. Salishchev, O.R. Valiakhmetov, R.M. Galeyev. J. Mater. Sci. 28, 2898 (1993).

16. R. M. Imayev, V. M. Imayev, G. A. Salishchev. J. Mater. Sci. 27, 4465 (1992).

17. R.M. Imayev, A.A. Nazarov, R.R. Mulyukov, G.F. Khasanova, R.M. Galeyev, O.R. Valiakhmetov. Letters on Materials. 4(4), 295 (2014). (in Russian)

18. O.R. Valiakhmetov, R.M. Galeyev, O.A. Kaibyshev, G. A. Salishchev. Patent RF No. 2224047. 20.02.2004. (in Russian)

19. R. M. Galeyev. Metally. 6, 19 (2005). (in Russian)

20. G.A. Salishchev, R.M. Galeyev, O.R. Valiakhmetov, R. V. Safiullin, R. Y. Lutfullin, O.N. Senkov, F.H. Froes, O. A. Kaibyshev. J. Mater. Process. Technol. 116, 265 (2001).

21. E. Avtokratova, O. Sitdikov, V. Markushev, R. Mulyukov. Mater. Sci.Eng. A. 538, 386 (2012).
22. F. Appel, R. Wagner. Mater. Sci. Eng. R22, 187 (1998).

23. J.D. H. Paul, F. Appel, R. Wagner. Acta Mater. 46, 1075 (1998).

24. R. Kainuma, Y. Fujita, H. Mitsui, I. Ohnuma, K. Ishida. Intermetallics. 8, 855 (2000).

25. Y. Mishin, Chr. Herzig. Acta Mater. 48, 589 (2000).

26. F. Appel, J. D. H. Paul, M. Oehring, U. Fröbel, U. Lorenz. Metall. Mater. Trans. 34A, 2149 (2003).

27. Ch. Herzig, T. Przeorski, M. Friesel, F. Hisker, S. Divinski. Intermetallics. 9, 461 (2001).

28. V. Imayev, R. Gaisin, A. Rudskoy, T. Nazarova, R. Shaimardanov, R. Imayev. J. Alloys Comp. 663, 217 (2016).

29. V.M. Imayev, A. A. Ganeev, R. M. Imayev. Intermetallics 101, 81 (2018).

30. O. A. Kaibyshev, R. Ya. Lutfullin, V. K. Berdin. Sov. Phys. Dokl. 36, 550 (1991).

31. O.A. Kaibyshev, R.V. Safiullin, R. Ya. Lutfullin, V.V. Astanin. J. Mater. Eng. Perform. 8, 205 (1999).

32. A. A.Kruglov, R. Ya.Lutfullin, M. Kh. Mukhametrakhimov, O. A. Rudenko, R. V. Safiullin. Perspektivnye Materialy. 6, 79 (2005). (in Russian)

33. D. G. Sanders, M. Ramulu. J. Mater. Eng. Perform. 13, 744 (2004).

34. L. D. Hefti. Mater. Sci. Forum. 551 - 552, 87 (2007).

35. P. N. Comley. Mater. Sci. Forum. 447 - 448, 233 (2004).

36. D. Sanders, P. Edwards, G. Grant, M. Ramulu, A. Reynolds. J. Mater. Eng. Perform. 19, 515 (2010).

37. D. Sanders, M. Ramulu, E. Klock-McCook, P. Edwards, A. Reynolds, T. Trapp. J. Mater. Eng. Perform. 17, 187 (2008).

38. M. Ramulu M., P.D. Edwards, D.G. Sanders, A. P. Reynolds, T. Trapp. Mater. Design. 31, 3056 (2010).

39. O.R. Valiakhmetov, R.M. Galeyev, V.A. Ivan'ko, R.M. Imayev, A.A. Inozemtsev, N.L. Koksharov, A.A. Kruglov, R. Ya. Lutfullin, R.R. Mulyukov, A. A. Nazarov, R. V. Safiullin, S. A. Kharin. Nanotechnol. Russia. 5, 108 (2010). DOI: 10.1134/S1995078010010118

40. A. Kh. Akhunova, S.V. Dmitriev, A.A. Kruglov, R. V. Safiullin. Perspektivnye Materialy. 12, 42 (2011). (in Russian) 